\title{
文化 IP 产业视阈下的高校人才培养模式探究
}

\author{
Research on the Talents Training Mode in Colleges and \\ Universities from the Perspective of Cultural IP Industry \\ 曹一帆 \\ Yifan Cao
}

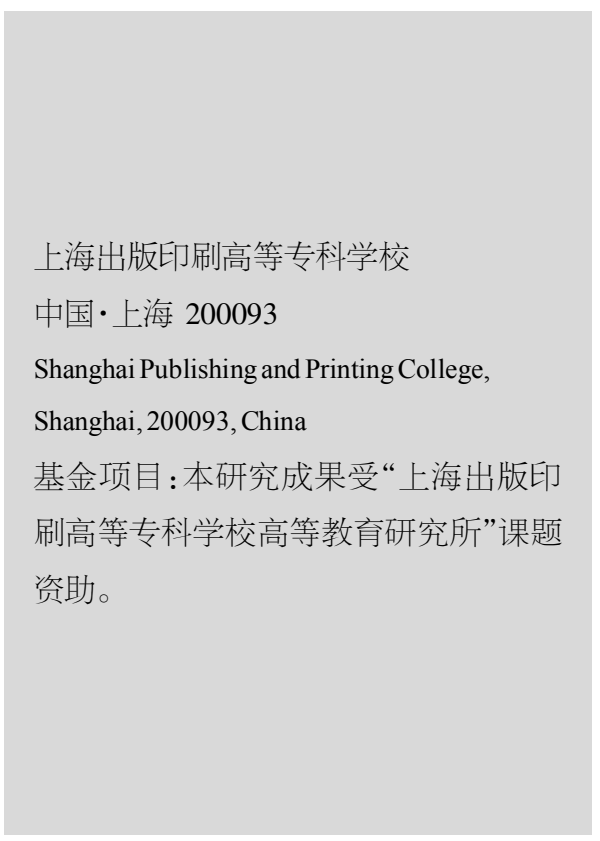

【摘要】文化产业成为国民经济支柱型产业, 产业的整体经济实力和竞争力越来越强, 文化类企业在深化挖掘和开发新型文化 IP 上加大筹码, 高价值、高流量的文化 IP 给企业 和社会带来了巨大的经济增长点。在文化产业快速发展的今天, 具有文化产业背景的复合 型人才成为文化就业市场上多手可热的香饽饽, 论文从当下高校的角度, 提出文化产业人 才培训的相关建议。

【Abstract】The cultural industry has become a pillar industry of the national economy, the overall economic strength and competitiveness of the cultural industry are getting stronger. Cultural enterprises was intensify efforts to excavation and development cultural IP. The cultural IP with high value and high flow will bring huge economic growth to the enterprise and the society. Today, with the development of cultural industry, compound talents with cultural industry background have become the hot demand in the cultural employment market. From the perspective of colleges and universities, this paper puts forward some suggestions on talent training in cultural industry.

【关键词】文化产业; 文化 IP; 人才培养

【Keywords】cultural industry; cultural IP; talent training 【DOI】10.36012/sde.v2i3.1604

\section{1 引言}

原中华人民共和国文化部在 2017 年对文化产业制定了 发展目标，称文化产业在 2020 年成为国民经济的支柱型产 业, 而 2020 年已经到来, 文化产业的整体实力和竞争力有了 明显的增强, 现在许多文化产业的关注点在如何把高文化价 值、高流量的文化 IP 转化变现。IP 是“知识产权 Intellectual Property”的缩写, 如今“IP” 的含义远远超过了它传统意义上 的知识产权的含义，它是建立在跨界互联网信息技术上的创 意产业的具体表现, 在中国, 它之所以快速成为国民经济新的 增长点, 这基于中国有一个巨大的网民基数和较先进的互联 网信息技术,这给文化 IP 加速转化做了很好的铺垫。在中国,
较早涉人且较为出名的 IP 产品转化的有郭敬明的 “小时代” 系列、多勿那年、同桌的你等影视剧目的改编, 随之而来是泛 娱乐业的上中下游的产业的具体化、细致化, 各大文化企业、 互联网企业以及有版权的出版行业纷纷加人这块创意产业的 大蛋糕中。

\section{2 高流量、高价值的文化 IP 变现成为国}

\section{民经济发展新动力}

可被开发的文化 IP 一般要具备以下几点:第一, 具有一 定的粉丝基础。这在文化产业中的各门类中都较为重要, 粉丝 群体的基数是文化 IP 转化后是否成功的重要考量指标, 想要 把“草根”做大做强, 早期就要依靠网络中的粉丝群体, 粉丝群 
体就像滚雪球, 越滚越大, 最终因其巨大的网络粉丝力量托举 成为明星 $I P$ 。如早期郭敬明的《小时代》系列, 这就是一个很 典型案例, 通过粉丝极高的忠诚度来消费, 最终实现 IP 转化 的过程, 《小时代》在图书市场和影视市场里形成了不可估量 的经济效益, 是一个极为成功的案例。第二, 文化 IP 多在网络 小说、网络游戏、综艺节目、传统故事及元素的场域里挖掘和 转化。从国家提倡振兴文化产业并出台一系列推动文化产业 经济增长的政策以来, 文化企业在不断地挖掘和开发文化 $\mathrm{IP}$, 较为成功地挖掘了一些大众喜闻乐见的文化项目和产品, 尤其值得关注的是在亚文化圈内, 一些后起之秀的 IP 进入了 主流文化的圈层, 慢慢走近人们的视野, 这些 IP 呈现出不同 的表现形态的多种玩法。例如, 网络文学, 网络文学是泛娱乐 IP 产业的最前端, 当泛娱乐业上下游打通时, 处于最前端的 网络文学最早出现在人们的视野, “2014 年底, 114 部网络小 说被购买了影视版权, 期中, 90 部计划拍成电视剧, 24 部计划 拍成电影” ${ }^{[1]}$, 次年的《华月传》《琅躯榜》《盗墓笔记》等都成为 版权运营的成功案例, 依托网络文学的多维度产品运营也是 文化类企业在不断摸索的新型发展之道。

\section{3 中国文化 IP 挖掘和开发的症结}

在中国, 好的文化 IP 非常多, 但是挖掘和开发这些文化 IP 的专业人才是有限的, 这就倒推了各大高校在培养文化人 才的目标上进行教育教学改革, 在注重专业知识技能的教育 之外, 更要注重其在未来职业岗位上的综合能力的培养, 尤其 是职业能力素质。“美国的文化产业专业创意人才为 $12 \%$, 英 国伦敦为 $14 \%$, 韩国文化产业人们在总就业人口的 $14 \%$, 人 才紧缺是中国后续在文化 IP 挖掘和开发上的关键问题。以上 海辞书出版社为例, 《辞海》是家喻户晓的中国最大的综合性 辞典, 2009 年之前《辞海》工具书的每年的销售是 100 多万 册, 2009 年之后是 40 万册, 而现在每年的销售只为 10 万册, 从具体数据上可以看出, 互联网的快速发展和电子工具书的 问世对传统工具书的冲击很大, 从趋势来看, 传统工具书将会 逐渐退出市场, 那么辞书社在应对市场变化的同时也在转型 升级, 他们面临的困难不仅是销售码洋的断崖式掉落, 更大的 困难是在数字化转型过程中人才的渴望, 由于传统出版社的 大部分在职人员是偏文科思维, 不利于出版社的转型发展, 在 互联网的浪潮下, 传统出版社渴望拥有即懂得出版产业又了 解互联网的技术人员, 在此基础上, 还迫切需要能够把《辞海》 这个超级文化 IP 开发设计的专业人才, 以小见大, 各大文化 类企业都面临着同样的问题，迫切需要文化产业相关人才去 开发优质文化 IP。

\section{4 高校作为人才培养源头, 该如何加强文 化 IP 人才的培养和参与文化项目的开发}

优质的 IP, 不仅要有好的内容, 更需要好的企业团队来 运营和打造, 在这个过程中, 文化 IP 挖掘和开发的相关人才 就是至关重要的, 如文化 IP 设计师, 这个职位包含了以下工 作内容: 第一, 在 IP 解构的过程中, 能够清晰地运用创意和设 计方法理清和看准产品的卖点; 第二, 能够精准地分析用户画 像及产品定位; 第三, IP 被开发后, 能够持续性的开发产品的 周边。对于文化 IP 人才的培养, 要培养能够满足文化企业对 于人才的要求, 既要重视专业技能的训练, 也重视人文科学素 养综合提升,在文化 IP 产业对应高校的学科建设上,较为匹 配的专业, 例如: 传播学、市场营销学、新闻学、艺术设计学等, 这些专业所属不同院系, 院系和专业的划分是以学科为依托, 当今文化产业的范围越来越广、涉及领域越来越宽, 就业市场 就要求拥有跨界、跨专业、跨领域的综合型人才, 对于文化产 业相关人才的要求也越来越高, 追本溯源, 在青年学子还在象 牙塔之时, 就要为其补充来自不同院系的王牌课程。其一, 为 了丰富知识结构, 补充本专业不会涉及的课程及知识点; 其 二, 为学生引导兴趣, 大学生往往在读书阶段会遇到专业迷 茫、就业迷茫的现象, 因为学生自己都不清楚自己想要什么或 者热爱什么, 这就要从课程人手, 好的老师、好的课程可以引 导一个学生在今后择业上发生改变, 因此, 补充不同学科的专 业课程是丰富学生知识储备的一个方法。

文化产业的人才培养, 高校要加强与就业市场对接, 不仅 是简单的校企合作, 把学生送进企业实习, 更要在校企合作上 挖掘深度合作的方法,如把“教室”搬到企业的“车间”, 以小班 “工作坊”的形式将文化产业中的创意策划、生产加工、市场营 销、延伸开发等内容贯穿在产业的全过程中,打造有特色的实 践教学, 着力提升学生的职业能力。现如今很多高校都有类似 “创新创业”的行政部门, 皆在指导学生创新创业, 但大学生在 创业过程中的艰难众人皆知, 在对文化产业人才培养的过程 中可以搭上 “创新创业”的船, 把创新创业的过程当作学习新 技能补充新知识的过程。因此, 高校在培养文化产业人才的过 程中, 可以利用“创新创业”部门的资源进行共享, 可单独开设 小班教学, 可以置换相应校选课的学分, 该教学手段更为灵 活, 学生对于知识和技能的获得感也更大。

\section{参考文献}

[1]陈琼. 文化 IP-在无形资产中创造价值[M]. 北京: 中国电影出 版社, 2017 .

[2]李圭,夏杰长,刘奕.文化产业人才的培养:需求分析与政策建 议[J].2018(54):3-10. 